\title{
Necessidades e usos da informação:a influência dos fatores cognitivos, emocionais e situacionais no comportamento informacional de gerentes
}

Frederico César Mafra Pereira

Economista (FACE/UFMG). Mestre e Doutorando em Ciência da Informação (ECI/UFMG) e Pós-graduado lato sensu em Gestão Estratégica de Marketing (CEPEAD/UFMG). Consultor Sênior da GLOBAL ON Consultores Associados. Professor em cursos de MBA e CBA no IBMEC-MG, IEC-PUCMinas e Faculdades Del Rey

Destaca a influência dos fatores cognitivos, emocionais e situacionais no comportamento informacional de gerentes. Foi proposto modelo baseado na abordagem perceptiva, estado anômalo de conhecimento, sense-making, busca de informação construtivista e uso da informação de valor agregado. Foi realizado estudo qualitativo junto a seis gerentes, de três organizações de grande porte de Belo Horizonte, através do método de entrevista da 'linha do tempo'. Os resultados confirmaram a aplicabilidade do modelo e da metodologia adotados, confirmando todas as suas etapas.

Palavras-chave: Necessidades e usos da informação; Comportamento informacional; Aspectos cognitivos; Aspectos emocionais; Aspectos situacionais.

\section{Information needs and uses: the influence of the cognitive, affective and situational aspects on the information behavior of managers}

The objective was to detach the influence of the cognitive, affective and situational aspects on the information behavior of managers. It was purposed a model based on a perceptive approach, anomalous state of knowledge, sense-making, construtivist search information and value-added and information use processes. A qualitative study with to six managers of the great three organizations located in Belo Horizonte was carried 
using the 'time-line' interview. The results brought us toward the applicability of the model and the methodology adopted.

Keywords: Information needs and uses; Information behavior; Cognitive aspects; Affective aspects; Situational aspects.

Recebido em 23.09.2008 Aceito em 18.10.2010

\section{Introdução}

Os estudos de usuários têm ampliado sua orientação e foco nos últimos anos na ciência da informação, em nível nacional e internacional, passando de uma orientação centrada em sistemas para uma centrada no usuário, deixando de focar em determinadas tarefas ou atividades de informação para entender a situação pessoal, social ou organizacional, na qual a informação precisa surgir e onde será posta em prática. Esse movimento de mudança pode ser visualizado no Brasil a partir da década de 80, quando uma nova abordagem começou a se desenvolver, denominada 'abordagem perceptiva' ou 'alternativa'. Nela, a informação é vista como algo construído pelo indivíduo e que só tem sentido quando integrada a um contexto. Esse indivíduo é visto como uma pessoa com um repertório cultural de conhecimentos, crenças e valores, necessidades cognitivas, afetivas e fisiológicas próprias, inserida em um ambiente com restrições socioculturais, políticas e econômicas. Suas dimensões de necessidades, esquemas de conhecimento e ambiente se constituem na base do contexto do comportamento de busca da informação (FERREIRA, 1995, p. 6).

Diante disso, o objetivo deste artigo foi identificar as necessidades do usuário de informação, com base em suas dimensões cognitivas, emocionais e situacionais e, ainda, apresentar algumas generalizações quanto aos fatores que influenciam seus processos de busca e uso da informação. O artigo foi estruturado em oito partes. Além desta introdução, na seção dois é feita uma retrospectiva sobre as abordagens tradicional e perceptiva, utilizadas em estudos de usuários. $\mathrm{Na}$ seção três é apresentado e discutido o modelo multifacetado de uso da informação de Choo (2003, p. 84), que permite a análise do processo de busca e uso da informação em três etapas: necessidades, busca e uso e, também, os efeitos das dimensões cognitivas, emocionais e situacionais sobre o indivíduo, nesse processo. Na seção quatro são discutidas tais dimensões e apresentadas as abordagens que serviram de referencial teórico-metodológico para a realização do estudo. Na seção cinco é proposto um modelo cuja estrutura foi aplicada junto ao público-alvo do trabalho e que serviu de base para a análise e interpretação dos dados. Na seção seis são detalhados os procedimentos metodológicos utilizados. $\mathrm{Na}$ seção sete são apresentados e analisados os resultados obtidos, com base no modelo proposto, sendo esse, inclusive, um dos resultados do trabalho. Por último, na seção oito, são feitas as considerações finais sobre o estudo.

\section{Estudos de usuários - as abordagens tradicional e perceptiva}


Os estudos de usuários têm ganhado força e crescido bastante, representando grande parcela dos estudos realizados na ciência da informação em nível nacional e internacional. Conforme Baptista e Cunha (2007, p. 169-170), o crescimento da literatura sobre estudos de usuários no Library and Information Science Abstracts (LISA) foi de quase 500\% entre 1970 e 2007. Em média, de 75,4 trabalhos/ano na década de 70, foi identificada uma média de 510 trabalhos/ano a partir de 2000 a 2007. Outra fonte de dados apresentada que confirma essa evolução é o Annual Review of Information Science and Technology (ARIST) com 19 artigos de revisão da literatura sobre o tema, em 16 volumes dos 41 já publicados.

Os primeiros estudos de usuários remontam à década de 50, desenvolvidos sob uma abordagem direcionada pela ótica do sistema de informação (MARTUCCI, 1997, p. 1; FERREIRA, 1995, p. 3), que considera a informação como algo externo, objetivo, que existe fora do indivíduo e pode ser definida, medida e utilizada por diferentes usuários da mesma forma, bastando ser descoberta. Ancorada no processo de comunicação tradicional, a informação (mensagem) é produzida por uma fonte e transmitida através de um canal com o objetivo de reduzir a ambiguidade. O usuário é visto como um dos integrantes do sistema, não a 'razão de ser' do serviço, posicionado passivamente e tendo de se adaptar aos sistemas de informação, planejados em função das tecnologias utilizadas para a sua implementação ou do conteúdo da informação a ser inserida nesses sistemas, ao invés de serem moldados às características dos usuários a quem deverá atender. Apesar dessa abordagem ter contribuído muito para a ciência da informação, não conseguiu responder questões relativas ao 'como' as pessoas fazem uso dos sistemas, 'para qual finalidade' e 'como' a informação obtida é utilizada pelo usuário. Segundo Ferreira (1995, p. 4), dois aspectos relativos a essa abordagem são questionáveis: 1) a irrelevância dada às incongruências entre o que está contido no problema do usuário e o que está contido na pergunta formulada; e 2) a falta de mecanismos nos sistemas de informação que consigam identificar como o usuário pretende usar a informação obtida e como ele define a sua relevância.

A partir da década de 80, uma nova abordagem centrada no usuário começou a se desenvolver no Brasil, denominada 'perceptiva' ou 'alternativa' (MARTUCCI, 1997, p. 2; FERREIRA, 1995, p. 5), baseada nas ideias: 1) a necessidade de informação deve ser analisada sob a perspectiva da individualidade do sujeito, sendo subjetiva e única, definida no plano pessoal; 2) a informação necessária e o esforço empreendido na sua busca devem ser contextualizados na situação real de seu surgimento (no tempo e no espaço de ocorrência); 3) o uso da informação deve ser dado e determinado pelo indivíduo que está em constante construção de seus sentidos. Dessa forma, o indivíduo é colocado como o centro do fenômeno a ser estudado, partindo-se de uma perspectiva cognitiva, buscando interpretar necessidades de informação tanto intelectuais quanto sociológicas (FERREIRA, 1995, p. 5). A informação é vista como algo construído pelo indivíduo, a qual dará o formato, a consistência e o sentido que Ihe convier, e só tem sentido quando integrada a um contexto. Para Ferreira (1995, p. 5), a informação é um dado incompleto, ao qual o usuário atribui um sentido a partir de seus esquemas anteriores de conhecimento, sendo 
um produto da observação da realidade. Sob a ótica dessa abordagem, o processo de comunicação é perceptivo e o indivíduo é visto como alguém com um repertório cultural de conhecimentos, crenças, valores, necessidades cognitivas, afetivas e fisiológicas próprias, inserida em um ambiente com restrições socioculturais, políticas e econômicas.

$\mathrm{Na}$ abordagem perceptiva os sistemas de informação devem ser concebidos sob a égide da flexibilidade, adaptando seu processo de busca da informação às necessidades do usuário (que podem mudar no tempo e serem diferentes entre os indivíduos). Martucci (1997, p. 3) destaca que os serviços de informação devem centrar no significado da busca mais do que na localização das fontes, em face ao aumento do acesso à grande quantidade de informação existente.

Torna-se cada vez mais importante procurar entender os elementos definidores dos estudos de usuários. Apesar de focarem as necessidades de informação no nível individual, é possível chegar a generalizações, a partir das percepções pessoais dos indivíduos pesquisados. Para Ferreira (1995, p. 7), existem muitas similaridades entre as situações vividas pelos diferentes indivíduos, sendo o conceito de necessidade de informação não somente subjetivo e existente apenas na mente de um indivíduo, mas "um conceito intersubjetivo com significados, valores, objetivos, etc., passíveis de serem compartilhados". Dessa forma, é possível a identificação e a generalização de padrões de comportamento de busca e uso de informação. Para Martucci (1997, p. 3), o indivíduo é uma "apropriação singular do universo social e histórico que o rodeia", sendo possível conhecer o social a partir das especificidades do indivíduo.

\section{0 modelo multifacetado de uso da informação de Choo}

Segundo Choo (2003, p. 83), o estudo das necessidades e usos da informação possui caráter transdisciplinar, proporcionando a existência de uma diversidade de pesquisas, abordagens e modelos. Por isso a importância de se constituir uma estrutura teórica, que surge como necessária para dar consenso sobre os elementos que definem a análise das necessidades e usos da informação pelos diversos usuários.

Um modelo de uso da informação deve englobar a totalidade da experiência humana: os pensamentos, sentimentos, ações e o ambiente onde eles se manifestam. Partimos da posição de que o usuário da informação é uma pessoa cognitiva e perceptiva; de que a busca e o uso da informação constituem um processo dinâmico que se estende no tempo e no espaço; e de que o contexto em que a informação é usada determina de que maneiras e em que medida ela é útil. (CHOO, 2003, p. 83)

O modelo proposto por Choo (2003, p. 83-84) é composto por três estágios. No primeiro, são examinados os ambientes onde a informação é processada e utilizada. O ambiente de processamento da informação é interno ao indivíduo e constituído por suas necessidades cognitivas e reações emocionais, enquanto o ambiente de uso é externo ao indivíduo e inclui as condições e atributos do meio profissional ou social que influenciam na busca e uso da informação pelo mesmo. 
No segundo estágio, são identificados alguns comportamentos referentes ao processo de busca e uso da informação pelo usuário, com a intenção de modificar o seu estado de conhecimento inicial. Quanto ao uso da informação, o comportamento típico é a seleção de informações relevantes que permitam a mudança no estado inicial de conhecimento do indivíduo ou na sua capacidade de agir. No terceiro estágio, são examinadas as interações entre os ambientes de processamento e uso da informação e cada um dos comportamentos de busca e uso apontados.

Destacam-se no modelo três propriedades de busca e uso da informação. Primeiramente, a forma e o objetivo dados à informação dependem das estruturas cognitivas e emocionais do indivíduo. Quanto ao aspecto cognitivo, o indivíduo constitui uma 'situação problema' e especifica limites, objetivos, meios, fatos e outros itens de maneira a delinear um espaço onde buscar a informação. Quanto ao aspecto emocional, os sentimentos do indivíduo (muitas vezes baseados em experiências passadas) o alertam sobre sinais importantes e que influenciam na preferência e seleção de determinadas fontes de informação, mensagens e estratégias de busca. Em segundo lugar, o uso dado à informação é situacional: o meio social e/ou profissional do indivíduo, os tipos de problemas enfrentados e o modo de resolver os problemas se combinam e estabelecem um contexto 'adequado' para o uso da informação, estabelecendo regras e normas que moldam os comportamentos, através dos quais a informação tornar-se-á útil. Em terceiro lugar, o uso da informação é dinâmico: a necessidade, a busca e o uso ocorrem em ciclos recorrentes, interagindo sem ordem predeterminada e de forma dinâmica com os elementos cognitivos, emocionais e situacionais do ambiente, sendo estes responsáveis pela alteração constante da percepção do indivíduo sobre o papel da informação e seus comportamentos de busca e uso, incluindo os critérios que utiliza para julgar uma informação válida (útil) ou não. O contexto é constantemente remodelado pelos efeitos da ação, criação de significado ou resultados do uso da informação.

\section{Dimensões cognitivas, emocionais e situacionais: abordagens}

\subsection{Dimensões cognitivas - abordagem de criação de significado}

O indivíduo é constituído de um quadro de referências interno, formado por suas experiências anteriores, conhecimentos prévios e significados interiorizados a partir de observações próprias da realidade e feitas por outros, além de um contexto sociocultural e profissional externo, no qual está inserido. Diante disso, o indivíduo produz sentido (cria significado) através de um processo lógico de percepção, compreensão, seleção, análise e interpretação da realidade e do mundo em que vive. Ao se confrontar com essa realidade, o indivíduo encontra ao longo do caminho barreiras, dilemas, confusões e desordens que causam descontinuidades a essa realidade. Para vencer e ultrapassar essas descontinuidades, lança mão de seus quadros de referência ('esquemas interiores'). Entretanto, quando esses esquemas não lhe permitem transpor os 
obstáculos identificados tornam-se inoperantes e o processo de busca por uma nova informação se coloca como necessário.

A abordagem de criação de significado ('sense-making'), desenvolvida por Brenda Dervin (1983a; 1983b; 1992), analisa como o indivíduo reconhece uma descontinuidade ou falta de habilidade para agir e compreender uma situação devido à falta de informação, e como procede à busca de informação para satisfazer sua necessidade. Na metáfora do 'sense-making', o indivíduo move-se continuamente no tempo e no espaço, vivenciando sua realidade como em uma estrada, dando passos por meio de suas experiências. A cada movimento é dado um novo passo e o indivíduo cria significado para as suas ações e o ambiente que o cerca. Esse movimento acontece enquanto o indivíduo consegue construir significados. Quando o movimento é interrompido por uma descontinuidade, o indivíduo para em uma situação e percebe a existência de um vazio cognitivo (lacuna). Nesse ponto, surge a necessidade de informação para a criação de novos significados e a transposição do vazio identificado (representado pela ideia da 'ponte'). O indivíduo, então, define a natureza do vazio cognitivo, interpreta-o e define as estratégias para transpô-lo.

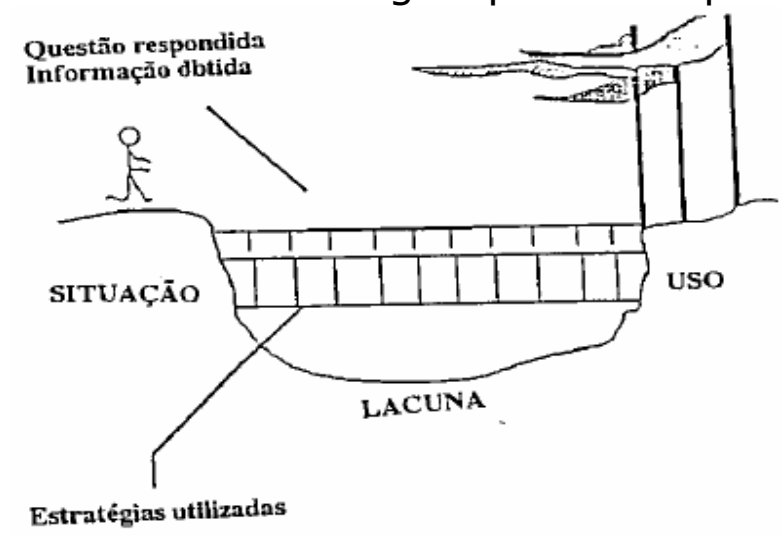

FIGURA 1 - A metáfora do sensemaking

Fonte: Adaptado de DERVIN (1992, p. 68).

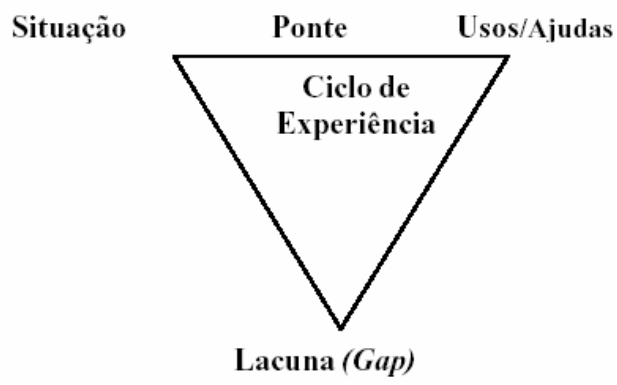

FIGURA 2 - Triângulo do sensemaking.

Fonte: Adaptado de DERVIN (1992, p.

$69)$.

A FIG. 2 representa o 'modelo de três pontas de DERVIN', constituído sob a ideia do trinômio 'situação-lacuna-ajuda' e mostra como o indivíduo se move através de suas experiências, sendo cada um desses momentos (pontas do triângulo), um momento de criação de sentido. A situação representa o contexto no tempo e espaço, no qual surge a necessidade de informação, sendo caracterizada como uma lacuna (ou 'gap') no conhecimento do indivíduo para solucionar o problema. Essa situação gera um estado de incerteza (reação emocional) e caracteriza um 'estado anômalo do conhecimento'. Segundo Belkin (1980, p.136), cada indivíduo possui um estado (ou estados) de conhecimento sobre determinado assunto e em determinado momento, sendo esse representado por uma estrutura de conceitos ligados por suas relações. No momento em que o indivíduo constata uma deficiência (ou anomalia) desse(s) conceitos, ele se encontra em um 'estado anômalo de conhecimento'. Ao obter 
uma informação ou um conjunto de informações que corrijam essa deficiência, o indivíduo cria um novo estado de conhecimento a ser aplicado na situaçãoproblema, provocando uma nova situação ou transformação de estruturas.

Para transpor a lacuna identificada, o indivíduo se utiliza de algum tipo de 'ponte', que corresponde às estratégias utilizadas para superá-la e que representam o processo de busca de informação, promovendo uma mudança no seu estado de conhecimento. A ajuda significa a utilização da informação obtida ao conhecimento recém adquirido, sendo essa informação considerada como 'informação útil'.

Através do método de pesquisa de entrevista da linha do tempo, o usuário é conduzido a reconstruir detalhadamente uma situação problema, o vazio detectado e a ajuda desejada. Para cada passo dado pelo indivíduo é realizada uma descrição com base no triângulo de criação de significado, identificando o micro-momento em que ele percebeu a situação-problema, identificou o 'gap' e a ajuda para transpô-lo (DERVIN, 1992, p. 70). Choo (2003, p. 87) aponta que os estudos realizados através dessa metodologia, concluíram que o comportamento de busca e uso da informação pode ser previsto quando se conhece o modo como o usuário percebe seus vazios cognitivos e como deseja informações que o ajudem a resolver a situação-problema. Esses estudos têm procurado desenvolver e aplicar categorias genéricas para descrição das situações-problema, lacunas e ajudas desejadas, que acabaram se estabilizando em alguns tipos (DERVIN, 1992, p. 75). A autora desenvolveu um conjunto de categorias denominadas 'paradas de situação', que descrevem a forma como os indivíduos vêem as barreiras que impedem o avanço no caminho. Diante delas, os indivíduos fazem perguntas com o objetivo de transpor as barreiras, sendo essas relacionadas com a localização dos acontecimentos no tempo e no espaço, para melhor entendimento das causas e determinação dos resultados esperados, além de procurar definir características dos indivíduos, acontecimentos e objetos (CHOO, 2003, p. 88). Por último, são desenvolvidas categorias que visam entender qual a ajuda (uso) os indivíduos imaginam ter.

\subsection{Dimensões emocionais: processo construtivista de busca da informação}

Paralelamente à percepção do usuário sobre suas necessidades cognitivas e a importância de superar suas lacunas de conhecimento, reações emocionais também fazem parte desse processo. Elas acabam por influenciar o processo de busca, canalizando a atenção para determinados tipos de informação, destacando opiniões, gostos ou aversões, revelando dúvidas e incertezas, motivando o esforço, dentre outros fatores. Um conceito fundamental para se entender as influências das dimensões emocionais no processo de busca de informação é o de 'incerteza' (KUHLTHAU, 1993, p. 347). Com base nesse conceito, Kuhlthau descreve o processo de busca de informação ('information search process - ISP') sob uma perspectiva construtivista, na qual a informação aparece para suprir um problema derivado de um estado de conhecimento anômalo. O sentimento de incerteza inicia esse processo, causando confusão, dúvida e ansiedade ao usuário. A ansiedade é associada ao 'gap' de conhecimento do indivíduo, principalmente 
quanto à utilização das fontes de informação e tecnologias (sistemas de informação). Kuhlthau (1991, p. 362) descreve um modelo que representa o processo de criação de significado na busca de informação e incorpora três arenas de atividades ou campos de experiência do usuário: arena física (cursos de ação tomados), arena afetiva (sentimentos e sensações experimentadas) e arena cognitiva (pensamentos relacionando o conteúdo e o contexto). Segundo a autora, o indivíduo move-se de um estado inicial de necessidade de informação para um estado de resolução de um problema, através de escolhas que perpassam por essas três arenas, sendo o critério de escolha influenciado por fatores como mudanças ambientais, experiência, conhecimento, interesse, avaliação da informação, requisitos do problema, tempo para solução, relevância da informação recuperada, dentre outros. O processo de busca de informação proposto por Kuhlthau (1991, p. 366) prevê seis estágios: 1) iniciação; 2) seleção; 3) exploração; 4) formulação; 5) coleta; e 6) apresentação.

\section{QUADRO 1}

Estágios do processo de busca de informação e os campos de experiência

\begin{tabular}{|c|c|c|c|c|}
\hline $\begin{array}{c}\text { Estágios do } \\
\text { ISP }\end{array}$ & $\begin{array}{c}\text { Tarefas } \\
\text { apropriadas }\end{array}$ & $\begin{array}{c}\text { ARENA COGNITIVA } \\
\text { Pensamentos } \\
\text { comuns }\end{array}$ & $\begin{array}{c}\text { ARENA } \\
\text { AFETIVA } \\
\text { Sentimentos } \\
\text { comuns }\end{array}$ & $\begin{array}{l}\text { ARENA FISICA } \\
\text { Ações comuns }\end{array}$ \\
\hline 1. INICIAÇÃO & $\begin{array}{l}\text { Reconhecer a } \\
\text { necessidade de } \\
\text { mais } \\
\text { informações }\end{array}$ & $\begin{array}{l}\text { 'Gap' de conhecimento } \\
\text { Pensamentos vagos e } \\
\text { ambíguos centrados no } \\
\text { problema geral ou área } \\
\text { de incerteza e } \\
\text { relacionados com } \\
\text { experiências passadas }\end{array}$ & $\begin{array}{l}\text { Incerteza e } \\
\text { apreensão }\end{array}$ & $\begin{array}{l}\text { Discutir possíveis } \\
\text { tópicos e abordagens }\end{array}$ \\
\hline 2. SELEÇÃO & $\begin{array}{l}\text { Identificar e } \\
\text { selecionar um } \\
\text { tópico ou tema } \\
\text { geral a ser } \\
\text { investigado }\end{array}$ & $\begin{array}{l}\text { Escolha de um tema } \\
\text { com probabilidade de } \\
\text { sucesso e capaz de } \\
\text { satisfazer critérios de } \\
\text { interesse pessoal, } \\
\text { informação disponível e } \\
\text { tempo alocado }\end{array}$ & $\begin{array}{l}\text { Otimismo e } \\
\text { prontidão para a } \\
\text { busca }\end{array}$ & $\begin{array}{l}\text { Conferir com outros e } \\
\text { buscar informações } \\
\text { secundárias dentro do } \\
\text { tema geral }\end{array}$ \\
\hline 3. EXPLORAÇÃO & $\begin{array}{l}\text { Expandir a } \\
\text { compreensão do } \\
\text { tema geral } \\
\text { através da } \\
\text { investigação das } \\
\text { informações }\end{array}$ & $\begin{array}{l}\text { Tornar-se bem } \\
\text { informado e orientado } \\
\text { para formular um foco } \\
\text { ou ponto de vista } \\
\text { pessoal }\end{array}$ & $\begin{array}{l}\text { Confusão, } \\
\text { incerteza e } \\
\text { dúvida podem } \\
\text { aumentar durante } \\
\text { a exploração; } \\
\text { Dois tipos de } \\
\text { incerteza: } \\
\text { conceitual e } \\
\text { quanto ao } \\
\text { processo de } \\
\text { recuperação da } \\
\text { informação } \\
\text { (interação } \\
\text { usuário e sist. } \\
\text { inf.); } \\
\text { Frustração e } \\
\text { inadequação } \\
\text { (caso o sist. de } \\
\text { inf. não atenda) }\end{array}$ & $\begin{array}{l}\text { Localizar informação } \\
\text { relevante para o tema } \\
\text { geral, ler para se tornar } \\
\text { informado e relacionar } \\
\text { a nova informação ao } \\
\text { que já sabe }\end{array}$ \\
\hline 4. FORMULAÇÃO & Estabelecer um & Pensamentos mais & Aumento da & Processo de busca e \\
\hline
\end{tabular}




\begin{tabular}{|c|c|c|c|c|}
\hline & $\begin{array}{l}\text { foco ou } \\
\text { perspectiva } \\
\text { sobre o } \\
\text { problema para } \\
\text { orientar a busca } \\
\text { da informação } \\
\text { explorada }\end{array}$ & $\begin{array}{l}\text { claros e mais } \\
\text { direcionados, com foco } \\
\text { formado sobre o } \\
\text { problema; envolve a } \\
\text { identificação e seleção } \\
\text { de idéias (formulação } \\
\text { de hipóteses num } \\
\text { processo de } \\
\text { construção) }\end{array}$ & $\begin{array}{l}\text { confiança e } \\
\text { diminuição da } \\
\text { incerteza; } \\
\text { Maior clareza }\end{array}$ & $\begin{array}{l}\text { pesquisa em etapas } \\
\text { (processo de } \\
\text { construção) }\end{array}$ \\
\hline 5. COLETA & $\begin{array}{l}\text { Interagir com } \\
\text { sistemas e } \\
\text { serviços de } \\
\text { informação para } \\
\text { reunir } \\
\text { informações }\end{array}$ & $\begin{array}{l}\text { Definir, estender e dar } \\
\text { suporte ao foco, } \\
\text { especificando } \\
\text { informações } \\
\text { particulares; } \\
\text { Interesse é } \\
\text { incrementado }\end{array}$ & $\begin{array}{l}\text { Aumento da } \\
\text { confiança e } \\
\text { interesse no } \\
\text { projeto } \\
\text { aprofunda-se } \\
\text { Senso de direção }\end{array}$ & $\begin{array}{l}\text { Juntar a informação } \\
\text { pertinente para o } \\
\text { problema focado }\end{array}$ \\
\hline $\begin{array}{l}6 . \\
\text { APRESENTAÇÃO }\end{array}$ & $\begin{array}{l}\text { Completar a } \\
\text { busca e resolver } \\
\text { o problema; } \\
\text { Preparar a } \\
\text { apresentação e } \\
\text { resultados para o } \\
\text { uso }\end{array}$ & $\begin{array}{l}\text { Término da pesquisa } \\
\text { com um entendimento } \\
\text { personalizado sobre o } \\
\text { problema investigado }\end{array}$ & $\begin{array}{l}\text { Alívio, realização } \\
\text { e satisfação (caso } \\
\text { a pesquisa tenha } \\
\text { atendido); } \\
\text { Desapontamento } \\
\text { (caso a pesquisa } \\
\text { não tenha } \\
\text { atendido) }\end{array}$ & $\begin{array}{l}\text { Pesquisa sumária na } \\
\text { qual é observada a } \\
\text { diminuição da } \\
\text { relevância e o aumento } \\
\text { da redundância nas } \\
\text { informações } \\
\text { encontradas }\end{array}$ \\
\hline
\end{tabular}

Fonte: Adaptado de KUHLTHAU (1991, p. 362); KUHLTHAU (1993, p. 343); CHOO (2003, p. 90).

Segundo Kuhlthau (1991; 1993), sentimentos de incerteza, confusão e frustração ocorrem nos primeiros estágios do processo, associados a pensamentos vagos e sem foco sobre o problema. À medida que o conhecimento sobre o tema fica mais claro e os pensamentos mais focados, sentimentos de confiança e certeza aumentam. Nos estágios finais do processo, sentimentos de satisfação e realização são comuns (caso o usuário tenha obtido êxito em seu processo de busca; caso contrário, o sentimento é de desapontamento). Portanto, o vazio cognitivo, caracterizado pelo sentimento de incerteza, impulsiona o processo de busca de informação e é acompanhado por diferentes estados emocionais. Choo (2003, p. 93) destaca que esses estados emocionais acabam por motivar e determinar a forma como o indivíduo processa e usa a informação, ao mesmo tempo em que também é influenciada pela capacidade do indivíduo em construir significado, dar foco à busca realizada, distinguir informações relevantes e irrelevantes, lidar com os aspectos emocionais e suas expectativas, e aprofundar seu interesse na pesquisa realizada.

\section{Dimensões situacionais: abordagem de valor agregado e uso da informação}

O comportamento informacional do indivíduo é também influenciado pelas dimensões situacionais, que incluem os requisitos, normas e expectativas inerentes ao trabalho do usuário e aos contextos organizacionais nos quais transita. Taylor (1986, p. 24) denomina esses contextos de 'ambientes de uso da informação', formados pelos elementos que afetam o fluxo e o uso das informações que chegam, saem ou circulam no interior de qualquer entidade e 
que determinam os critérios pelos quais o valor das informações é julgado ${ }^{1}$ (CHOO, 2003, p. 93). Os elementos que compõem os ambientes de uso da informação são agrupados em quatro categorias (TAYLOR, 1991): os grupos de pessoas, as dimensões do problema, o ambiente de trabalho e os pressupostos para a solução de problemas (QUADRO 2).

\section{QUADRO 2}

Categorias e elementos dos ambientes de uso da informação

\begin{tabular}{|c|c|c|c|}
\hline $\begin{array}{l}\text { GRUPOS DE } \\
\text { PESSOAS }\end{array}$ & DIMENSÕES DO PROBLEMA & $\begin{array}{l}\text { AMBIENTES DE } \\
\text { TRABALHO }\end{array}$ & $\begin{array}{l}\text { PRESSUPOSTOS PARA A } \\
\text { SOLUÇÃO DE PROBLEMAS }\end{array}$ \\
\hline $\begin{array}{l}\text { 1. Profissionais } \\
\text { 2. Empresários } \\
\text { 3. Grupos de interesse } \\
\text { 4. Grupos sócio- } \\
\text { econômicos especiais }\end{array}$ & $\begin{array}{l}\text { * Os problemas são dinâmicos } \\
\text { * Diferentes tipos de problemas são criados } \\
\text { por força da profissão, cargo, condição } \\
\text { social, etc. } \\
\text { *As dimensões do problema determinam os } \\
\text { critérios para julgar o valor da informação }\end{array}$ & $\begin{array}{l}\text { * Estrutura e estilo da } \\
\text { organização } \\
\text { * Campo de interesse } \\
\text { * Acesso à informação } \\
\text { * História, experiência }\end{array}$ & $\begin{array}{l}\text { * Pressupostos sobre o que constitui } \\
\text { a resolução de um problema } \\
\text { * Modos de uso da informação } \\
\text { " Atributos da informação esperados } \\
\text { para solucionar um problema }\end{array}$ \\
\hline
\end{tabular}

Fonte: Adaptado de CHOO (2003, p. 84)

Os grupos de pessoas possuem atitudes e conceitos pré-definidos sobre a natureza do trabalho que influenciam seu comportamento de busca por informação e que são aprendidos de maneira formal (educação, treinamento profissional) ou informal (participando de um grupo ou sociedade). As dimensões do problema representam as características que preocupam determinado grupo, variando de acordo com cada ambiente de uso e com as características e exigências de cada grupo envolvido. Segundo Choo (2003, p. 95), os problemas representam as demandas mais evidentes do ambiente de uso da informação e, quando é possível definir suas dimensões, é também possível inferir sobre as necessidades de informação de forma mais sistemática (tanto do indivíduo quanto da situação em que está envolvido). Os ambientes de trabalho são constituídos pelas características físicas e sociais da empresa ou setor no qual um grupo trabalha e que influenciam suas atitudes quanto à informação, seus tipos, estruturas requeridas, seu fluxo e sua disponibilidade. O estilo e a cultura da empresa também ajudam a moldar as percepções dos indivíduos sobre o papel e a importância da informação (CHOO, 2003, p. 96). Por último, os pressupostos para a solução dos problemas representam as percepções compartilhadas por um grupo sobre o que constitui a solução dos problemas identificados e orientam a busca e o uso da informação sob diversas formas. Segundo Taylor (1991), apud Choo (2003, p. 97), a forma como os indivíduos definem seus problemas e antecipam suas soluções se constitui em um meio consistente de controlar a quantidade de informação a ser buscada e utilizada (extensão e profundidade da busca de informação)

\section{Modelo para identificação das necessidades, busca e uso da informação}

1 Taylor (1982, p.342) denomina de 'informação com valor agregado' a informação obtida através do processo de transformação dos dados da busca em informação útil. 
Como resultado da integração das abordagens e dimensões apontadas, foi desenvolvido e elaborado um modelo teórico para identificação das necessidades, busca e uso da informação, cuja estrutura foi aplicada junto ao público-alvo deste trabalho, através das técnicas de pesquisa definidas, servindo também de base para a análise e interpretação dos dados obtidos (FIG. 3).

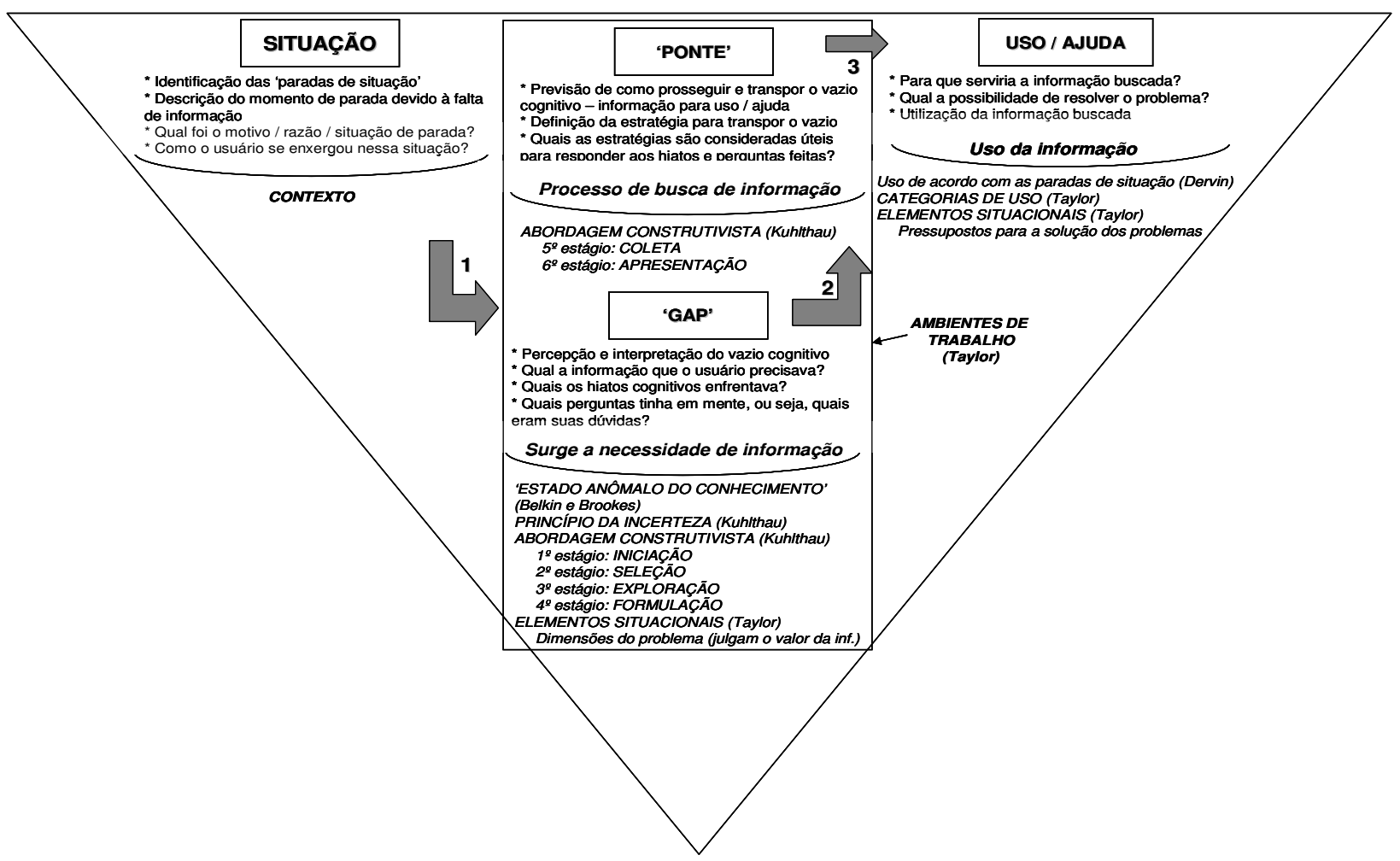

FIGURA 3 - Modelo teórico para identificação das necessidades, busca e uso da informação.

Fonte: Desenvolvido pelo autor e adaptado de DERVIN (1992); KUHLTHAU (1991); TAYLOR (1986; 1991) e CHOO (2003).

\section{Procedimentos metodológicos}

Este trabalho teve como público-alvo gerentes de empresas públicas e privadas de grande porte, atuantes no mercado de Belo Horizonte (MG), cuja escolha justificou-se pelo fato dos mesmos serem responsáveis pela tomada de decisão gerencial em seus negócios. Foi utilizada a abordagem de pesquisa qualitativa ${ }^{2}$ através da realização de 06 (seis) entrevistas individuais em profundidade, junto a gerentes de 03 (três) tipos de organizações de grande porte - duas entrevistas com gerentes de uma empresa privada, duas entrevistas em uma instituição pública e duas entrevistas com gerentes de uma organização civil, sem fins lucrativos, selecionados através de amostra não-probabilística, por

2 Em estudos de usuários de informação, Baptista e Cunha (2007, p.173) destacam que a pesquisa qualitativa focaliza a atenção nas causas das reações dos usuários e na resolução de problemas informacionais, além dos aspectos subjetivos da experiência e do comportamento humano, com um enfoque mais holístico do que o método quantitativo de pesquisa. A coleta de dados qualitativos é vista mais como um processo do que um procedimento. 
julgamento. As entrevistas seguiram um roteiro de perguntas semiestruturado, de forma a orientar o trabalho. Na primeira parte do roteiro, através do método de pesquisa de entrevista da linha do tempo, o usuário foi conduzido a reconstruir uma situação problema, o vazio detectado e a ajuda desejada, descrevendo todos os passos detalhadamente e observando-se o local e o tempo dos acontecimentos. Buscou-se trabalhar com todas as abordagens e conceitos destacados no modelo teórico proposto. Na segunda parte do roteiro, os gerentes foram solicitados a indicarem as influências que determinam a busca e o uso da informação em seus diversos contextos. Mesmo não sendo o objetivo quantificar as respostas dadas pelos entrevistados, foi feito um 'ranking' das alternativas, que sinalizaram as influências que mais impactam o processo de busca e uso da informação pelos gerentes entrevistados.

Para a análise dos dados, foi também utilizado como referência o modelo teórico proposto. Para cada etapa do modelo de criação de significado de Dervin a situação, o 'gap', a 'ponte' e o uso/ajuda - foram analisados os aspectos identificados em cada empresa pesquisada e, quando pertinente, em cada entrevista realizada. Em todas essas etapas também foram identificadas as reações emocionais presentes em cada micromomento do processo de busca de informação e verificada a existência (ou não) dos estágios propostos por Kuhlthau, em seu modelo construtivista (ISP). Todas as etapas e respectivas análises foram desenvolvidas considerando também as categorias e os elementos do ambiente de uso da informação apontados por Taylor e a sua influência nos processos de busca avaliados.

\section{Resultados obtidos: análise e comentários}

Uma primeira constatação do trabalho foi a de que o 'modelo de três pontas' de Dervin, apresentou-se de grande valia para o estudo proposto, sendo todas as suas etapas identificadas e caracterizadas claramente através das entrevistas realizadas. Além disso, o método de pesquisa de entrevista da linha do tempo se mostrou pertinente e permitiu que fossem identificadas, em cada micromomento do processo de busca de informação pelos gerentes, as paradas de situação, as lacunas e barreiras, as confusões, sentimentos e emoções, as dúvidas, as estratégias de busca e os estágios correspondentes, além do modo como a informação foi usada para a solução da necessidade de informação identificada.

Em relação à primeira etapa do modelo - a 'situação-problema', os resultados demonstraram que as 'paradas de situação' definidas por Dervin se confirmaram, especialmente com relação aos tipos 'parada de decisão' e 'parada de barreira', que demandavam tomadas de decisão e aquisição de capacidades para um melhor desenvolvimento das atividades. Além disso, estavam diretamente conectadas ao contexto de trabalho dos gerentes, nas três organizações pesquisadas, não havendo diferenças entre as situações destacadas pelos gerentes de uma mesma organização (QUADRO 3).

\section{QUADRO 3}

Etapa de identificação da 'situação-problema' 


\begin{tabular}{ccc}
\hline Empresa privada & Instituição pública & Organização civil \\
\hline $\begin{array}{c}\text { Necessidade de melhoria dos } \\
\text { processos operacionais e de } \\
\text { atendimento ao cliente }\end{array}$ & $\begin{array}{c}\text { Necessidade de conhecimento para } \\
\text { desenvolvimento de treinamento } \\
\text { de equipe e melhoria da motivação }\end{array}$ & $\begin{array}{c}\text { Necessidade de } \\
\text { investimentos em } \\
\text { tecnologia para melhoria de } \\
\text { processos }\end{array}$ \\
\hline
\end{tabular}

Fonte: Dados da pesquisa.

As necessidades identificadas foram corroboradas na segunda etapa da entrevista, quando os gerentes ordenaram as que mais influenciavam, de forma geral, seus processos de busca de informações. Em todas as seis entrevistas realizadas, as necessidades de informação que mais influenciavam o processo de busca e uso pelos gerentes estavam relacionadas ao ambiente de trabalho / atividade profissional e ao processo de tomada de decisão no ambiente de trabalho.

Em relação à segunda etapa do modelo - o 'gap', os resultados demonstraram que os gerentes não tiveram dificuldades em perceber e interpretar os vazios cognitivos decorrentes das situações identificadas, nem em definir adequadamente as necessidades de informação de cada uma. Entretanto, as reações emocionais identificadas, bem como os estágios inicialmente previstos pelo modelo de Kuhlthau, divergiram um pouco do previsto no modelo da autora.

\section{QUADRO 4}

Etapa de identificação do 'gap': reações emocionais e estágios do processo de busca

\begin{tabular}{|c|c|c|c|}
\hline & Empresa privada & Instituição pública & Organização civil \\
\hline $\begin{array}{c}\text { Percepção e } \\
\text { interpretação do 'GAP' / } \\
\text { lacuna }\end{array}$ & $\begin{array}{c}\text { Necessidade de } \\
\text { informações técnicas, } \\
\text { operacionais e de } \\
\text { processos para } \\
\text { verificação de } \\
\text { 'gargalos', } \\
\text { esclarecimento de } \\
\text { dúvidas com vistas à } \\
\text { melhoria do } \\
\text { atendimento }\end{array}$ & $\begin{array}{c}\text { Necessidade de } \\
\text { informações sobre } \\
\text { doenças no trabalho e } \\
\text { fatores motivacionais } \\
\text { para desenvolvimento } \\
\text { de ações e } \\
\text { treinamento de } \\
\text { equipe }\end{array}$ & $\begin{array}{c}\text { Necessidade de } \\
\text { informações técnicas } \\
\text { e comerciais sobre } \\
\text { produtos (hardware e } \\
\text { software) para } \\
\text { embasar decisão de } \\
\text { compra }\end{array}$ \\
\hline $1^{\circ}$ estágio: INICIAÇÃO & $\begin{array}{c}\text { Identificado } \\
\text { (ambas as entrevistas) }\end{array}$ & $\begin{array}{l}\text { Identificado } \\
\text { (ambas as } \\
\text { entrevistas) }\end{array}$ & $\begin{array}{l}\text { Identificado } \\
\text { (ambas as } \\
\text { entrevistas) }\end{array}$ \\
\hline 20 estágio: SELEÇÃO & $\begin{array}{c}\text { Identificado } \\
\text { (ambas as entrevistas) }\end{array}$ & $\begin{array}{l}\text { Identificado } \\
\text { (ambas as } \\
\text { entrevistas) }\end{array}$ & $\begin{array}{l}\text { Identificado (em } \\
\text { apenas uma } \\
\text { entrevista) }\end{array}$ \\
\hline $\begin{array}{l}\text { Reações emocionais } \\
\text { nos primeiros estágios }\end{array}$ & $\begin{array}{c}\text { Ansiedade e } \\
\text { insegurança (ambas as } \\
\text { entrevistas) }\end{array}$ & $\begin{array}{l}\text { Curiosidade (1 } \\
\text { entrev.) e } \\
\text { tranquilidade (1 } \\
\text { entrev.) }\end{array}$ & $\begin{array}{c}\text { Desânimo (1 entrev.) } \\
\text { e Urgência ( } 1 \\
\text { entrev.) }\end{array}$ \\
\hline $\begin{array}{l}30 \text { estágio: } \\
\text { EXPLORAÇÃO }\end{array}$ & $\begin{array}{c}\text { Identificado } \\
\text { (ambas as entrevistas) }\end{array}$ & $\begin{array}{l}\text { Identificado } \\
\text { (ambas as } \\
\text { entrevistas) }\end{array}$ & Não identificado \\
\hline $\begin{array}{l}40 \text { estágio: } \\
\text { FORMULAÇÃOO }\end{array}$ & $\begin{array}{c}\text { Identificado } \\
\text { (ambas as entrevistas) }\end{array}$ & $\begin{array}{l}\text { Identificado } \\
\text { (ambas as } \\
\text { entrevistas) }\end{array}$ & Não identificado \\
\hline
\end{tabular}


Fonte: Dados da pesquisa.

Kuhlthau aponta para a existência de sentimentos de incerteza e apreensão, seguidos de otimismo e prontidão para a busca, nos estágios iniciais do processo de busca (iniciação e seleção). Conforme demonstrado no QUADRO 4, os resultados da pesquisa apontam para a existência de sentimentos de ansiedade e insegurança em três entrevistas, sendo duas referentes à empresa privada e uma à organização civil. Quanto aos gerentes da organização civil, ambos os sentimentos eram relacionados ao fator tempo: desânimo (por ter que buscar, selecionar e avaliar informações técnicas em várias fontes) e urgência (por não ter tempo para a realização de uma busca aprofundada). Pode-se inferir que o sentimento de urgência provocou ansiedade na busca. Quanto aos supervisores da instituição pública, os sentimentos identificados foram de curiosidade em pesquisar sobre o tema definido e até tranquilidade em relação à certeza e segurança de que encontrariam as informações necessárias nas fontes escolhidas. Nesse caso, os sentimentos identificados não coincidem com os previstos pelo modelo da autora.

Quanto aos estágios do processo de busca definidos por Kuhlthau, nas seis entrevistas realizadas foi possível identificar, de forma clara, o primeiro estágio de iniciação (conforme QUADRO 4). Quanto aos estágios seguintes - seleção, exploração e formulação, observou-se que, de forma geral, os gerentes passavam do estágio inicial direto para o estágio da formulação e nas situações em que passaram pelos estágios de seleção e exploração, realizaram atividades de forma conjunta, não havendo uma clara definição de atividades e etapas que caracterizassem os estágios como definido pelo modelo. Na prática, os estágios de seleção, exploração e formulação, quando ocorrem (ou quando são identificados), são difusos e não tão claramente demarcados. Na organização civil, apenas um gerente realizou ações no estágio de seleção; os demais estágios foram desconsiderados, sendo iniciada a coleta logo após o início do processo (identificação da necessidade).

Em relação à terceira etapa do modelo - a 'ponte', os resultados demonstraram que as estratégias utilizadas pelos gerentes para superarem o ' $g a p^{\prime}$ se basearam nas ações previstas pelos estágios de coleta e apresentação do processo de busca de informação. Em cinco das seis entrevistas foi identificado o uso da Internet e da Intranet para a busca das informações necessárias. No caso da Internet, ela foi utilizada como uma fonte de referência para a pesquisa em sites de busca e de empresas fornecedoras (gerentes da instituição pública e da organização civil). No caso da Intranet (ou Portal Corporativo), seu uso foi de grande valia para os gerentes da empresa privada, como fonte de informação para a busca de documentação técnica e operacional (vide QUADRO 5). 


\section{QUADRO 5}

Definição das estratégias para superação do 'gap' / 'construção da ponte'

\begin{tabular}{|c|c|c|c|}
\hline & Empresa privada & Instituição pública & Organização civil \\
\hline $\begin{array}{l}\text { Como prosseguir } \\
\text { e transpor o vazio } \\
\text { cognitivo - 'ponte' }\end{array}$ & $\begin{array}{l}\text { * Busca na Intranet / } \\
\text { Portal } \\
\text { * Contato com outros } \\
\text { supervisores e } \\
\text { gerentes da empresa } \\
\text { (busca de opiniões e } \\
\text { confronto de idéias } \\
\text { para tomada de } \\
\text { decisão) }\end{array}$ & $\begin{array}{l}\text { * Busca na Internet } \\
\text { (seleção prévia dos } \\
\text { sites e fontes a } \\
\text { serem } \\
\text { pesquisados) } \\
\text { * Leitura do } \\
\text { material }\end{array}$ & $\begin{array}{l}\text { * Busca na Internet } \\
\text { (sites de fornecedores) } \\
{ }^{\star} \text { Comparação de } \\
\text { especificações } \\
\text { * Busca no arquivo } \\
\text { físico } \\
\text { * Troca de informações } \\
\text { com especialistas }\end{array}$ \\
\hline $\begin{array}{l}\text { 5o estágio: } \\
\text { COLETA }\end{array}$ & $\begin{array}{l}\text { Identificado } \\
\text { (ambas as } \\
\text { entrevistas) }\end{array}$ & $\begin{array}{l}\text { Identificado } \\
\text { (ambas as } \\
\text { entrevistas) }\end{array}$ & $\begin{array}{c}\text { Identificado } \\
\text { (ambas as entrevistas) }\end{array}$ \\
\hline $\begin{array}{c}\text { 60 estágio: } \\
\text { APRESENTAÇÃ } \\
\text { O }\end{array}$ & $\begin{array}{l}\text { Identificado } \\
\text { (ambas as } \\
\text { entrevistas) }\end{array}$ & $\begin{array}{l}\text { Identificado } \\
\text { (ambas as } \\
\text { entrevistas) }\end{array}$ & $\begin{array}{l}\text { Identificado } \\
\text { (em ambas as } \\
\text { entrevistas) }\end{array}$ \\
\hline $\begin{array}{c}\text { Reações } \\
\text { emocionais nos } \\
\text { últimos estágios }\end{array}$ & $\begin{array}{c}\text { Ansiedade e } \\
\text { confiança } \\
\text { Tranquilidade e } \\
\text { satisfação } \\
\text { (ambas as } \\
\text { entrevistas) } \\
\end{array}$ & $\begin{array}{c}\text { Expectativa, } \\
\text { interesse } \\
\text { Ansiedade, êxito e } \\
\text { alívio } \\
\text { (ambas as } \\
\text { entrevistas) } \\
\end{array}$ & $\begin{array}{c}\text { Cansaço e ansiedade } \\
\text { Alívio e satisfação } \\
\text { (ambas as entrevistas) }\end{array}$ \\
\hline
\end{tabular}

Fonte: Dados da pesquisa.

Em relação à quarta e última etapa do modelo proposto - o uso / ajuda, os resultados demonstraram que em todos os casos pesquisados as informações obtidas foram úteis e serviram para a resolução das respectivas situaçõesproblema. Os sentimentos oriundos dessa última etapa também se confirmaram similares aos apontados por Kuhlthau. Quanto às categorias destacadas por Taylor sobre os ambientes de uso da informação, algumas poucas diferenças foram identificadas, comparando os resultados obtidos com o modelo proposto por esse autor. 


\section{QUADRO 6}

Uso da informação: categorias de uso e elementos situacionais

\begin{tabular}{|c|c|c|c|}
\hline & Empresa privada & Instituição pública & Organização civil \\
\hline $\begin{array}{l}\text { Utilização da } \\
\text { informação } \\
\text { buscada / } \\
\text { resolução da } \\
\text { situação- } \\
\text { problema }\end{array}$ & $\begin{array}{l}\text { * Tomada de decisão } \\
\text { sobre procedimentos } \\
\text { adequados e } \\
\text { investimentos para } \\
\text { melhoria do } \\
\text { atendimento ao } \\
\text { cliente }\end{array}$ & $\begin{array}{c}{ }^{*} \text { Realização de } \\
\text { treinamentos } \\
\text { técnicos e } \\
\text { motivacionais }\end{array}$ & $\begin{array}{l}\text { * Decisão de compra } \\
\text { de um servidor e } \\
\text { renovação de } \\
\text { licenças de softwares }\end{array}$ \\
\hline \multicolumn{4}{|l|}{ CATEGORIAS } \\
\hline $\begin{array}{l}\text { GRUPOS DE } \\
\text { PESSOAS }\end{array}$ & $\begin{array}{l}\text { Gerentes têm } \\
\text { processos e } \\
\text { comportamentos } \\
\text { semelhantes de } \\
\text { busca da inf. }\end{array}$ & $\begin{array}{l}\text { Gerentes têm } \\
\text { processos e } \\
\text { comportamentos } \\
\text { semelhantes de } \\
\text { busca da inf. }\end{array}$ & $\begin{array}{c}\text { Gerentes possuem } \\
\text { objetivos e processos } \\
\text { diferentes na busca } \\
\text { de inf. }\end{array}$ \\
\hline $\begin{array}{l}\text { PROBLEMAS } \\
\text { TÍPICOS }\end{array}$ & $\begin{array}{l}\text { Dimensões do } \\
\text { problema e critérios } \\
\text { de valor da inf. } \\
\text { claramente definidos }\end{array}$ & $\begin{array}{l}\text { Dimensões do } \\
\text { problema e critérios } \\
\text { de valor da inf. } \\
\text { claramente definidos }\end{array}$ & $\begin{array}{l}\text { Dimensões do } \\
\text { problema e critérios } \\
\text { de valor da inf. } \\
\text { claramente definidos }\end{array}$ \\
\hline $\begin{array}{l}\text { AMBIENTES DE } \\
\text { TRABALHO }\end{array}$ & $\begin{array}{c}\text { Ambiente de trabalho } \\
\text { influencia as atitudes } \\
\text { quanto à inf. } \\
\text { (necessidades, } \\
\text { busca e uso) }\end{array}$ & $\begin{array}{c}\text { Ambiente de trabalho } \\
\text { influencia as atitudes } \\
\text { quanto à inf. } \\
\text { (necessidades, } \\
\text { busca e uso) }\end{array}$ & $\begin{array}{c}\text { Ambiente de trabalho } \\
\text { influencia as atitudes } \\
\text { quanto à inf. } \\
\text { (necessidades, } \\
\text { busca e uso) }\end{array}$ \\
\hline $\begin{array}{l}\text { PRESSUPOSTO } \\
\text { S PARA A } \\
\text { SOLUÇÃO DE } \\
\text { PROBLEMAS } \\
\end{array}$ & $\begin{array}{l}\text { Pressupostos e } \\
\text { percepções } \\
\text { compartilhados e } \\
\text { atendidos } \\
\end{array}$ & $\begin{array}{l}\text { Pressupostos e } \\
\text { percepções } \\
\text { compartilhados e } \\
\text { atendidos }\end{array}$ & $\begin{array}{l}\text { Pressupostos e } \\
\text { percepções } \\
\text { compartilhados e } \\
\text { atendidos }\end{array}$ \\
\hline
\end{tabular}

Fonte: Dados da pesquisa.

Conforme o QUADRO 6, na categoria 'grupo de pessoas' verificou-se que os gerentes da empresa privada e da instituição pública apresentaram atitudes comuns sobre a natureza de seu trabalho e que influenciaram seu comportamento de busca por informação. Entretanto, os gerentes da organização civil não demonstraram essa 'sintonia' de pressupostos e atitudes em relação ao processo de busca: enquanto um gerente procurou informações na Internet e comparou-as para levá-las à apreciação da diretoria, o outro gerente pesquisou no arquivo físico da organização e, não tendo encontrado as informações que buscava, solicitou a ajuda de especialistas. Na categoria 'problemas típicos' verificou-se que todos os seis gerentes pesquisados conseguiram definir de forma clara os seus 
problemas, bem como os critérios utilizados para julgar o valor da informação a ser obtida.

$\mathrm{Na}$ categoria 'ambientes de trabalho', verificou-se que as características físicas e sociais das empresas pesquisadas influenciaram as atitudes dos gerentes com relação à informação (identificação das necessidades, processos de busca e uso). Todos os seis gerentes afirmaram que o ambiente de trabalho / profissional é o fator que mais influencia as suas necessidades de informação e pelo fato de ocuparem cargos de gerência em suas empresas, essa influência se torna ainda mais forte, principalmente para os processos de busca e uso da informação voltados à tomada de decisão. Na última categoria, os pressupostos e percepções dos gerentes sobre o que se constituía a solução de seus problemas foram bem definidos e orientaram de maneira adequada a busca e o uso da informação. Em todos os casos pesquisados as informações obtidas foram úteis e serviram para a resolução das situações-problema.

\section{Considerações finais}

O modelo teórico desenvolvido e proposto nesse artigo serviu de referencial para a realização do estudo, sendo, inclusive, um dos seus produtos. Recomendase a aplicação do mesmo em outros contextos e outras categorias profissionais para a confirmação de sua validade. Verificou-se também a aplicabilidade dos conceitos oriundos do 'modelo de três pontas' de Dervin, dos estágios do processo de busca da informação de Kuhlthau e das categorias e elementos dos ambientes de uso da informação de Taylor, sendo todos os modelos e aspectos identificados e caracterizados através das entrevistas realizadas, servindo de base para a estruturação do modelo teórico proposto.

O método de pesquisa de entrevista da linha do tempo se mostrou pertinente e permitiu que fossem identificadas, em cada micromomento do processo de busca de informação pelos gerentes, as paradas de situação, as lacunas e barreiras, as confusões, sentimentos e emoções, as dúvidas, estratégias de busca e os estágios correspondentes, além do uso dado à informação para a solução da necessidade identificada. O uso da abordagem de pesquisa qualitativa através da realização de entrevistas individuais em profundidade também se mostrou adequada. Recomenda-se a adoção de outras técnicas, como a observação in loco, para a verificação dos aspectos identificados na práxis dos gerentes. Nesse sentido, mostra-se também importante a realização de estudos longitudinais para que seja possível medir as variações de uso e as necessidades de informação ao longo de um prazo maior de tempo.

Quanto aos resultados alcançados, verificou-se, primeiramente, que as 'paradas de situação' definidas por Dervin se confirmaram e estavam diretamente relacionadas ao processo de tomada de decisão e ao ambiente de trabalho dos seis gerentes, nas três organizações pesquisadas. Em segundo lugar, as lacunas de conhecimento identificadas e as informações necessárias para resolvê-las foram definidas de forma objetiva pelos gerentes, não havendo dificuldades em perceber e interpretar os vazios cognitivos decorrentes das situações identificadas, nem em definir adequadamente as necessidades de informação de cada uma. Quanto aos estágios do processo de busca, nas seis entrevistas 
realizadas foi possível identificar, de forma clara, o primeiro estágio de iniciação; e os estágios de seleção, exploração e formulação, que quando ocorrem (ou quando são identificados), são difusos e não tão claramente demarcados. Em terceiro lugar, as estratégias utilizadas pelos gerentes para superarem o 'gap' se basearam nas ações previstas pelos estágios de coleta e apresentação, sendo a Internet e a Intranet utilizadas por cinco, dentre os seis gerentes pesquisados para a busca das informações. Por último, em todos os casos pesquisados as informações obtidas foram úteis e serviram para a resolução das respectivas situações-problema, sendo algumas poucas diferenças identificadas quanto às categorias e elementos destacados por Taylor em seu modelo sobre os ambientes de uso da informação, comparados aos resultados obtidos.

\section{Referências}

BAPTISTA, S. G.; CUNHA, M. B. Estudo de usuários: visão global dos métodos de coleta de dados. Perspectivas em Ciência da Informação, Belo Horizonte, v. 12, n. 2, p. 168-184, maio/ago. 2007.

BELKIN, N. J. Anomalous states of knowledge as a basis for information retrieval. Canadian Journal of Information Science, v. 5, p. 133-143, 1980.

CHOO, C. W. A Organização do Conhecimento: como as organizações usam a informação para criar significado, construir conhecimento e tomar decisões. São Paulo: SENAC, 2003.

DERVIN, B. An overview of sense-making research: concepts, methods, and results to date. In: INTERNATIONAL COMMUNICATION ASSOCIATION ANNUAL MEETING. Dallas: Department of Communication, Ohio State University, Columbus, May 1983a. Disponível em: $<$ http://www.ideals.uiuc.edu/html/2142/2281/Dervin83a.htm $>$. Acesso em 29 fev. 2008.

Information as a user construct: the relevance of perceived information needs to synthesis and interpretation. In: WARD, S. A.; RED, L. J. (Orgs.). Knowledge structure and use: implication for synthesis and interpretation. Philadelphia: Temple University Press, 1983b. p.153-183.

. From the mind's eye of the user: the sense-making qualitativequantitative methodology. In: GLAZIER, J. D.; POWELL, R. R. (Orgs.). Qualitative research in information management. Englewood: Libraries Unlimited, 1992. p.61-84.

FERREIRA, S. M. S. P. Novos paradigmas e novos usuários de informação. Ciência da Informação, v. 25, n. 2, p. 1-10, 1995.

KUHLTHAU, C. C. Inside the search process: information seeking from the user's perspective. Journal of the American Society for Information Science, v. 42, n. 5, p. 361-371, 1991.

A principle of uncertainty for information seeking. Journal of Documentation, v. 49, n. 4, p. 339-355, 1993. 
MALHOTRA, N. K. Pesquisa de Marketing: uma orientação aplicada. $3^{a}$ ed. Porto Alegre: Bookman, 2001.

MARTUCCI, E. M. Abordagem sense-making para estudo de usuário. Porto Alegre: ABEBD - Associação Brasileira de Ensino de Biblioteconomia e Documentação da UFRGS, 1997.

MATTAR, F. N. Pesquisa de marketing. São Paulo: Atlas, 1996

TAYLOR, R. S. Value-added processes in the information life cycle. Journal of the American Society and Information Science, v.33, n.5, p.341-346, 1982.

TAYLOR, R. S. Value-added processes in information systems. Norwood: Ablex Publishing, 1986.

. Information use environments. In: DERVIN, B.; VOIGT, M. J. (Orgs.). Progress in communication science. Norwood: Ablex Publishing, 1991.

TRIVIÑOS, A. N. S. Introdução à pesquisa em ciências sociais: a pesquisa qualitativa em educação. 3a ed. São Paulo: Atlas, 1992. 